\title{
Mechanical Pruning and Soil Organic Amending in Two Terroirs. Effects on Wine Chemical Composition and Sensory Profile
}

\author{
Manuel Botelho, ${ }^{1,2 *}$ Henrique Ribeiro, ${ }^{1,2}$ Amândio Cruz, ${ }^{2}$ Daniel F. Duarte, ${ }^{1,2}$ \\ Diana L. Faria, ${ }^{1,2}$ Kaushal S. Khairnar, ${ }^{2}$ Rafaela Pardal, ${ }^{2}$ Marta Susini, ${ }^{2}$ \\ Carlos Correia, ${ }^{2}$ Sofia Catarino, ${ }^{1,2}$ Jorge Cadima, ${ }^{2}$ Rogério de Castro, ${ }^{2}$ \\ and Jorge M. Ricardo-da-Silva ${ }^{1,2}$
}

\begin{abstract}
The knowledge about the interaction between mechanical pruning and soil organic amending is still scarce. This study aimed to examine the effects of the interaction between these two practices on wine quality. Syrah grapes from two trial fields in Portugal subjected to two different pruning systems (mechanical pruning; hand spur pruning) and five different organic amendment treatments (control, biochar, municipal solid waste compost, cattle manure, and sewage sludge) were harvested and vinified for four years. Mechanical pruning significantly reduced wine alcoholic strength, $\mathrm{pH}$, and total anthocyanins. Mechanical pruning and organic amendments, tendentially reduced wine total phenols and tannin power, known as an "estimation of the astringency potential of the wines". Tasters found low but significant differences in global appreciation with the pruning system. Sludge tended to reduce wine global appreciation more than municipal solid waste compost and cattle manure, while biochar had no effect on tasters' preference when compared to the control. There was strong relation between yield and tasters' preference only above $6 \mathrm{~kg} / \mathrm{vine}$ and $8 \mathrm{~kg} / \mathrm{vine}$ depending on the terroir. Mechanical pruning tendentially has significant effects on wine quality when yield raises above a certain level. Thus, with this pruning system, the choice of the organic amendment and its amount must be done considering the destiny of the produced grapes. To the best of our knowledge, effects of the interaction of mechanical pruning with soil organic amending on wine quality are a novelty.
\end{abstract}

Key words: fertilization, pruning, sensory discrimination, Syrah, wine composition

The increase in yield generally originated by mechanized pruning systems (Sims et al. 1990, Keller and Mills 2007) is not normally connected with the loss of grape and wine quality (Sims et al. 1990) except when the canopy efficiency does not compensate the rise of production (Poni et al. 2004). In a wine market that requires higher efficiency and competitiveness, a pruning system that produces grapes with overall

${ }^{1}$ LEAF, Linking Landscape, Environment, Agriculture and Food, Instituto Superior de Agronomia, Universidade de Lisboa, Tapada da Ajuda, 1349-017 Lisboa, Portugal; and ${ }^{2}$ Instituto Superior de Agronomia, Universidade de Lisboa, Tapada da Ajuda, 1349-017 Lisboa, Portugal.

*Corresponding author (mbotelho@isa.ulisboa.pt)

Acknowledgments: Research funded by ProDeR (Measure 4.1 "Cooperation for Innovation", PA 24071, Partnership 397, FERTILPODA Project), by PDR2020 (Measure 1.0.1/2016, partnership n 82 , initiative 164), by Caixa Geral de Depósitos and ISA (doctoral grant to Manuel Botelho). This work was also funded by FCT - Foundation for Science and Technology under the project UID/AGR/04129/2020 (LEAF) and DL 57/2016/CP1382/CT0025.

Supplemental data is freely available with the online version of this article at www.ajevonline.org.

Manuscript submitted April 2021, revised Sept 2021, accepted Sept 2021

This is an open access article distributed under the CC BY license (https:// creativecommons.org/licenses/by/4.0/)

By downloading and/or receiving this article, you agree to the Disclaimer of Warranties and Liability. The full statement of the Disclaimers is available at http://www.ajevonline.org/content/proprietary-rights-notice-ajev-online. If you do not agree to the Disclaimers, do not download and/or accept this article. doi: 10.5344/ajev.2021.21019 unaffected yield and composition is a reliable tool for improving vine growers' economic performance.

The application of organic amendments affects the chemical properties of soils, increasing the availability of nutrients (Fangueiro et al. 2012, Illera-Vives et al. 2015), changing the nutrient status of the vine, and affecting wine composition (Morlat and Symoneaux 2008).

The effects of nitrogen $(\mathrm{N})$, which can be supplied by the mineralization of organic matter, have already been extensively studied. In terms of grape and wine composition, high levels of $\mathrm{N}$ delay grape maturation (Hilbert et al. 2003, Morlat and Symoneaux 2008), which can be related to higher yields (Spayd et al. 1994) and/or to the increase in plant vigor, which affects carbon partitioning favoring vegetative growth in detriment of reproductive growth (Delgado et al. 2004, Bell and Henschke 2005). Excessive N supply tends to decrease total soluble solids (TSS), increase or maintain $\mathrm{pH}$, maintain titratable acidity, and decrease polyphenol content (Spayd et al. 1994, Delgado et al. 2004, Morlat and Symoneaux 2008) even in low vigor vineyards (Gatti et al. 2020).

Organic amendments - particularly sewage sludge (Sludge) - also supply phosphorus (P), the effects of which on grapevines are not widely studied because grapevines require only small quantities of this nutrient. The $\mathrm{P}$ application to soil is regulated in Portugal and in many other areas. Conradie and Saayman (1989) found no differences in grape composition with P fertilization. However, Kakegawa et al. (1995) observed that when in excess, P may inhibit the induction of 
phenylalanine ammonia-lyase and chalcone synthase activity, leading to a reduction of anthocyanin content of berries.

Potassium $(\mathrm{K})$ is another macronutrient that is usually supplied by organic amendments. Mpelasoka et al. (2003) report that although a relationship between TSS and berry K content can be established, it is not clear that high levels of $\mathrm{K}$ in berries have a positive correlation with sugar accumulation. Most of the already performed works report no effects of $\mathrm{K}$ supply on grape sugar content (Conradie and Saayman 1989, Delgado et al. 2004). High levels of $\mathrm{K}$ in berries increase must and wine $\mathrm{pH}$ (Conradie and Saayman 1989, Mpelasoka et al. 2003). However, the influence in total acidity is not consensual because some authors found a reduction of this variable (Mpelasoka et al. 2003, Delgado et al. 2004), while others observed an increase (Conradie and Saayman 1989), or even no influence (Freeman and Kliewer 1983).

Organic amendments also have a role on micronutrient availability in soil. With a long-term application of biosolids, Richards et al. (2011) observed a significant increase of soil extractable copper $(\mathrm{Cu})$, iron $(\mathrm{Fe})$, molybdenum $(\mathrm{Mo})$, and zinc $(\mathrm{Zn})$, while with the application of cattle manure, an increase in the levels of boron (B), $\mathrm{Cu}, \mathrm{Fe}$, manganese (Mn), Mo, and Zn was observed. Zhang et al. (2015) report that manure plus inorganic fertilizers applied to soil significantly augmented soil-available $\mathrm{Fe}, \mathrm{Mn}, \mathrm{Cu}$, and $\mathrm{Zn}$ contents relative to controls.

Not many studies have been performed regarding the effects on grape and wine quality with the application of municipal solid waste compost (MSWC) and Sludge. However, Messiga et al. (2016) observed no differences in grape sugar content and phenolics with the application of $13.4 \mathrm{t} / \mathrm{ha}$ of municipal solid food waste. Pinamonti (1998) observed no differences in grape quality of Merlot with the application of MSWC and Sludge.

Biochar (Bioc) is known to increase nutrient retention in soil (Lehmann et al. 2003), reduce the bioavailability and phytotoxicity of heavy metals (Park et al. 2011), improve plant water availability (Baronti et al. 2014), improve soil structure, and stimulate soil microbial activity (Sánchez-Monedero et al. 2019). In general, this leads to low but significant increases in crop productivity $(\sim 10 \%)$ across different crops, soils, biochar types, and application rates (Jeffery et al. 2011). The effects of biochar application in vineyard soil on grape and wine quality has not been extensively studied as yet. However, existing studies point to a lack of effects on grape and wine quality parameters (Sánchez-Monedero et al. 2019).

According to the reviewed literature, mechanical pruning seems to be an appropriate strategy to face the increasing scarcity of skilled hand-labor, to decrease production costs and increase productivity while organic amendments increase productivity, address the problems associated with predicted climatic changes, and, when obtained from human residues (i.e., residues from human settlements), are a tool to implement circular economy. However, the interaction between mechanical pruning and soil organic amending have significant effects in vegetative and reproductive growth (Botelho et al. 2020) as well as in grape composition (Botelho et al. 2021).
Consequently, it is likely that the interaction between these two practices can affect wine quality, and the present work aims to evaluate it.

\section{Materials and Methods}

Site description, experimental design, and yield assessment. The trial, run over four years (2012 to 2015), was installed in two vineyards of Vitis vinifera L. cv. Syrah in Portugal: Quinta do Côro (QC) in the Tejo wine region, and Quinta do Gradil (QG) in the Lisboa wine region. The vineyards and the cultural practices adopted are described in Botelho et al. (2020).

The soil in QC was a Hypereutric Regosol (USS Working Group WRB 2015) with a sandy-loam texture, $\mathrm{pH} \mathrm{H}_{2} 0$ of 6.4, low organic matter content (1.54\%), and extractable $\mathrm{K}$ and $\mathrm{P}$ contents of $70.7 \mathrm{mg} \mathrm{K} / \mathrm{kg}$ and $59.8 \mathrm{mg} \mathrm{P} / \mathrm{kg}$ (ammonium lactate extraction [Egnér et al. 1960]), respectively. The QG soil was also a Hypereutric Regosol (USS Working Group WRB 2015 ) with sandy-loam textures, a $\mathrm{pH}_{2} \mathrm{O}$ of 5.9, low organic matter content $(1.07 \%)$, and extractable $\mathrm{K}$ and $\mathrm{P}$ contents of $167.0 \mathrm{mg} \mathrm{K} / \mathrm{kg}$ and $61.2 \mathrm{mg} \mathrm{P} / \mathrm{kg}$ (ammonium lactate extraction [Egnér et al. 1960]), respectively. The climate in QC is a Csa (temperate with rainy winters and hot, dry summers) and in QG is a Csb (temperate with rainy winters and mild, dry summers), according to the Köppen-Geiger climate classification (IPMA 2020). Monthly total rainfall and mean air temperature data during the course of the study are presented in Botelho et al. (2020).

The studied factors were pruning system and organic amendments that were compared in a strip-plot design with three blocks (Figure 1). Each block held eight adjacent rows where pruning treatment was randomly assigned, creating two groups of four adjacent lines each with a different pruning treatment. The $60-\mathrm{m}$ rows were divided in five parts of 12 $\mathrm{m}$ each, where organic amendments were randomly distributed. Each of the 30 plots consisted of 48 vines.

Two pruning treatments were imposed during the entire experiment: manual spur pruning (MAN), retaining six to seven two-bud spurs per vine; and mechanical pruning (MEC), simulating the pruning effect of four cutting bars

\begin{tabular}{|c|c|c|c|c|c|}
\hline MEC & Ctrl & MSWC & Bioc & Manure & Sludge \\
\hline MAN & Ctrl & MSWC & Bioc & Manure & Sludge \\
\hline MAN & Bioc & Sludge & Ctrl & MSWC & Manure \\
\hline MEC & Bioc & Sludge & Ctrl & MSWC & Manure \\
\hline MEC & Sludge & MSWC & Manure & Ctrl & Bioc \\
\hline MAN & Sludge & MSWC & Manure & Ctrl & Bioc \\
\hline
\end{tabular}

Figure 1 Experimental design of the trials installed in each of the two sites (Quinta do Côro and Quinta do Gradil). Pruning system: hand pruning (MAN) and mechanical pruning (MEC). Organic amendments: control (Ctrl), biochar (Bioc), municipal solid waste compost (MSWC), cattle manure (Manure), and sewage sludge (Sludge). 
(two parallel and two perpendicular to the ground) working at a distance of $15 \mathrm{~cm}$ from the cordon.

In relation to organic amendments, five treatments were imposed during the years of the experiment: the control (Ctrl) — no application of organic amendment or fertilizer; biochar (Bioc) - application of $8500 \mathrm{~kg} / \mathrm{ha} /$ year of char dust resulting from the pyrolysis of wood; MSWC - application of $16,100 \mathrm{~kg} / \mathrm{ha} /$ year; cattle manure (Manure) — application of $24,000 \mathrm{~kg} / \mathrm{ha} /$ year; and sewage sludge (Sludge) — application of $34,000 \mathrm{~kg} / \mathrm{ha} /$ year. The referred quantity of each organic amendment is expressed in fresh weight and its definition was based on the application of $5000 \mathrm{~kg}$ of dry organic matter per hectare and per year. The composition of each organic amendment is presented in Botelho et al. (2020).

To estimate yield, six vines per experimental unit were harvested and the production weight per plant was assessed.

Winemaking. In both trial fields, grapes from the three replicates per treatment, respectively, were pooled for winemaking. Sixteen $\mathrm{kg}$ of grapes were harvested per plot and pooled, thus $48 \mathrm{~kg}$ of grapes were used for each treatment. Twenty vinifications were performed each year, to obtain 10 wines from each experimental site.

Before the harvest, the grapes from the vineyards involved in this project were monitored to assess their quality and maturation stage. The parameters controlled in this phase were the weight of 100 berries in grams $(\mathrm{g}), \mathrm{TSS}$, potential alcohol content $(\%), \mathrm{pH}$, and total acidity (g tartaric acid/L). Total anthocyanins and total phenols in grapes were assessed also at harvest. The results of grape analysis before fermentation are presented in Botelho et al. (2021).

When the grapes were at the ideal stage of maturation, the manual harvest was performed on the same day for all treatments, and the grapes were transported to the experimental winery of Instituto Superior de Agronomia in Lisbon, Portugal, where the vinification took place. On the same day of harvest, grapes were destemmed, crushed, and sulfur dioxide was added $(50 \mathrm{mg} / \mathrm{L})$. The crushed grapes were placed into 60-L stainless steel tanks and inoculated with the yeast Zymasil Bayanus (AEB). After these operations, a sample of must from each vineyard and treatment was taken to analyze potential alcoholic content, $\mathrm{pH}$, and total acidity.

The alcoholic fermentation lasted between seven and nine days at the average temperature of $24^{\circ} \mathrm{C}$, and the maceration time was extended to 15 days in all treatments. During this period, the cap was punched down three times a day. After maceration, the skins were separated from the juice using a vertical press, and pressed juice was added to the freerun juice. When alcoholic fermentation ended, wines were analyzed to determine classical parameters such as alcoholic content, $\mathrm{pH}$, total acidity (TA), volatile acidity, and free and total $\mathrm{SO}_{2}$.

The malolactic fermentation spontaneously developed after the alcoholic fermentation, and its progression was followed using paper chromatography (Ribéreau-Gayon et al. 1982) to monitor the presence of malic and lactic acids in the wines. In February, this process was ended for all the wines. To remove the lees that settled, the wines were racked and then a new analysis took place to control total and free $\mathrm{SO}_{2}$, volatile acidity, and $\mathrm{pH}$. Free $\mathrm{SO}_{2}$ content was then adjusted to $30 \mathrm{mg} / \mathrm{L}$ and the wines were stored in $750 \mathrm{~mL}$ bottles.

After the bottling process, the wine's chromatic characteristics, phenolic composition, and sensory analysis were performed.

Classical chemical parameters. The wine analysis was performed in the Enology Laboratory of Instituto Superior de Agronomia. Alcoholic content (distillation and densimetry), total acidity (titration with sodium hydroxide with bromothymol blue as indicator), fixed acidity (FA), volatile acidity (steam distillation followed by acid-base titrimetry), total and free $\mathrm{SO}_{2}$ (by titration with iodine), and reducing substances (clarification with neutral lead acetate, reaction with alkaline copper salt solution and iodometry) in wines were analyzed according to OIV described methods (OIV 2021).

Color parameters and phenolic compounds evaluation. Color intensity (sum of absorbencies at 420, 520, and 620 $\mathrm{nm}$ wavelengths) and hue (ratio of absorbencies at $420 \mathrm{~nm}$ and $520 \mathrm{~nm}$ wavelengths) were analyzed according to OIV described methods (OIV 2021).

Total and ionized anthocyanins, total and polymeric pigments, total phenols, and tannin power were analyzed according to the following procedures: i) Total and ionized anthocyanins (mg/L) and total and polymeric pigment (a.u.) determinations were performed by spectrophotometry according to the methodology developed by Somers and Evans (1977), using sodium metabisulfite solution (20\%) in the first part, and $\mathrm{HCl}(1 \mathrm{M})$, in the second part. ii) Total phenols index (a.u.) were analyzed according to the methodology proposed by Somers and Evans (1977), which consists of measuring the absorbance at wavelength $280 \mathrm{~nm}$ (A280) of the diluted wine sample. iii) Tannin power $(\mathrm{NTU} / \mathrm{mL})$ - a way to estimate the potential astringency of a wine-was determined by the method developed by De Freitas and Mateus (2002), which measures the turbidity caused by the aggregates of tannins and proteins by nephelometry (nephelometer Hach $2100 \mathrm{~N}$, Hach Co.), after adding bovine serum albumin to cause the precipitation.

For the quantification of $\mathrm{K}$, inductively coupled plasma optical emission spectrometry (model iCAP 7000 Series, Thermo Fisher Scientific) was used. The samples were previously diluted 1:10 as described by Zioła-Frankowska and Frankowski (2017).

Descriptive sensory analysis. Each wine sample was stored for $24 \mathrm{hrs}$ at room temperature before sensory analysis, which was performed at 20 to $22^{\circ} \mathrm{C}$ in a sensory analysis room with individual booths for each expert. Each of these booths were equipped with fluorescent lights and tables with white surfaces (ISO 8589:2007). All evaluations were conducted in the morning from 1000 to $1200 \mathrm{hr}$. Twelve expert judges with wine tasting experience, most of them winemakers, evaluated the wine samples during a single sensory evaluation session nine months after the harvest of each year. In each session, wines from the two sites were divided in two flights that were tasted with a $20 \mathrm{~min}$ interval. Each wine was served in tasting glasses (ISO 3591:1977) coded with a 
random three-digit code and filled with $25 \mathrm{~mL}$ of wine at a temperature of $18^{\circ} \pm 2^{\circ} \mathrm{C}$. Wines were presented to the tasters in a randomized order. Water and crackers were used as palate cleansers.

All expert judges were previously selected and trained during a six-month training period. During this period, several sessions were carried out to train judges on the meaning of each attribute and achieving intensity rating in a reliable way. The procedures for monitoring the performance of the panel are described in ISO 11132:2012; the practices are explained in general guidelines for the selection, training, and monitoring of selected assessors and expert sensory assessor in ISO 8586:2012.

The sensory attributes used were the following: color ("red" and "violet"); aroma ("fruit," "floral," "vegetal," "jam," "intensity," and "balance"); taste ("body," "bitterness," "astringency," "acidity," "persistency," and "balance"); and "global appreciation" (i.e., the "balance", "harmony", or "overall judgment" of each wine, as evaluated by the panel judges, by taking into consideration all sensory attributes evaluated previously).

The experts scored each sensory attribute on the following five-point scales: nonexistent (0), not very intense (1), moderately intense (2), intense (3), and very intense (4); mediocre (0), satisfactory (1), good (2), very good (3), excellent (4), this scale was only used for "balance," of aroma and taste, and "global appreciation."

Statistical analysis. All data were tested to verify if the assumptions of analysis of variance (ANOVA) were fulfilled using Shapiro-Wilk's test, then were subjected to three-way (pruning $\times$ organic amendment $\times$ site) ANOVA using the general linear procedure for strip-split-plot design and $\mathrm{F}$ test. The significance level was set at $\alpha=0.05$ and means were separated using Tukey's honest significant difference test. The statistical analysis was performed using Statistix software package (version 9.0; Analytical Software). Regression analysis was used to study relationships between continuous variables, and the curves were fit using the least squares method.

In the tables presented in the Results section, the values presented for the pruning system are an average of 10 wines (two sites $\times$ five organic amendments), while for the organic amendment the average was for four wines (two sites $\times$ two pruning systems), and for site the presented values are an average of 10 wines (two pruning systems $\times$ five organic amendments).

\section{Results}

The results presented in this paper correspond only to the last three years (harvests) of the research project because in 2012, no significant effects were observed in grape and wine composition. The main outcomes concerning grape and wine composition from the first experimental year (2012) were reported by Correia (2014). The grape composition is presented in Botelho et al. (2021).




Classical chemical parameters. The interaction between the pruning system and organic amendments was not significant in any of the evaluated physicochemical characteristics.

The alcoholic strength (Table 1 and Supplemental Table 1) shows a significant decrease in MEC when compared to MAN, although in 2015 the differences were significant only in the QC site (Supplemental Table 2). Regarding the organic amendments effect, significant differences were observed only in 2015 when Sludge had lower alcoholic strength (11.9\% vol.), MSWC and Manure had an intermediate behavior (13.2 and $13.0 \%$ vol., respectively), and $\mathrm{Ctrl}$ and Bioc presented the highest values (14.0 and 13.8\% vol., respectively).

The $\mathrm{pH}$ (Table 1 and Supplemental Table 1) was significantly reduced by MEC every year, but in 2013 the differences were significant only in QG, and in 2015 only in QC (Supplemental Table 2).

Regarding TA and FA (Table 1 and Supplemental Table 1), there are significant increases of these variables in MEC treatments, with the exception of FA in 2013. The analysis of the interaction between pruning system and site, which except for TA in 2014 is always significant, shows that in 2013 the difference of TA is significant only in QG, and in 2014 and 2015, only in QC (Supplemental Table 2).

Volatile acidity (Table 1 and Supplemental Table 1) was affected by pruning only in 2015, and MAN wines presented higher values ( $15 \%$ more).

Mechanical pruning originated a significant reduction of $\mathrm{K}$ content of wines (Table 1 and Supplemental Table 1) in 2013 and 2014, while the organic amendment had a significant effect only in 2013. Concerning the organic amendments, a reduction of wine K content in Sludge was observed. Regarding the differences between sites, there is a significantly higher $\mathrm{K}$ content in QG in all the studied years, with differences that are between $13.1 \%$ (2015) and 20.9\% (2014).

In Figure 2, the relation between yield and wines' alcoholic strength is presented. Throughout the study, there is a tendency for a decrease in wines' alcoholic strength with the increase of yield. There is a difference between QC and $\mathrm{QG}$, which is constant; the covariance analysis shows that the lines of the two sites are parallel, with QG wines having less alcohol when compared to QC. The relationship between the two variables is relatively high, especially in QC. The $\mathrm{pH}$ has a negative relation with yield in both sites (Figure 3), although in QG that relation is more negative than in QC. Figure 4 illustrates the regression of FA on yield and the results show a weak correlation between both variables.

Color parameters and phenolic compounds. The imposed treatments had few effects on color intensity and color hue of wines (Table 2 and Supplemental Table 3). However, in 2014 color hue was significantly lower in MEC (11\% less). The significant differences found in color hue in 2014, due to the pruning system, occurred only in the QC experimental site (Supplemental Table 4). Regarding the organic amendments effect, significant differences were observed in color intensity only in 2015 when Sludge had lower color intensity (6.4 a.u.); MSWC, Manure, and Bioc had an intermediate behavior; and Ctrl presented the highest values of this variable

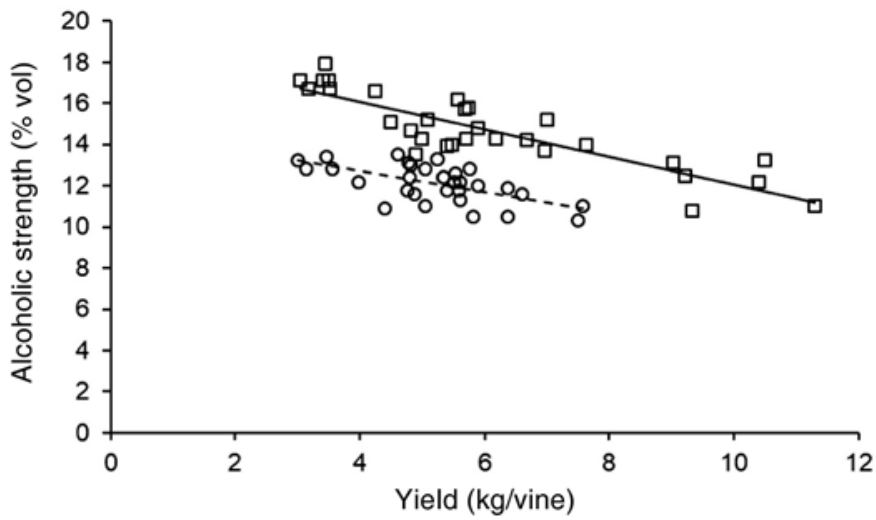

Figure 2 Influence of the site on the relation between yield and alcoholic strength of Syrah wines. Data represent single treatment (pruning system $\times$ organic amendment $\times$ site) averages and data were pooled over repetitions: $\square$-Quinta do Côro (QC); $\bigcirc$ - Quinta do Gradil (QG). Regression equations:

$y=-0.67 x+18.79, r^{2}=0.76, p<0.0001(Q C)$;

$y=-0.51 x+14.75, r^{2}=0.38, p=0.0003(Q G)$.

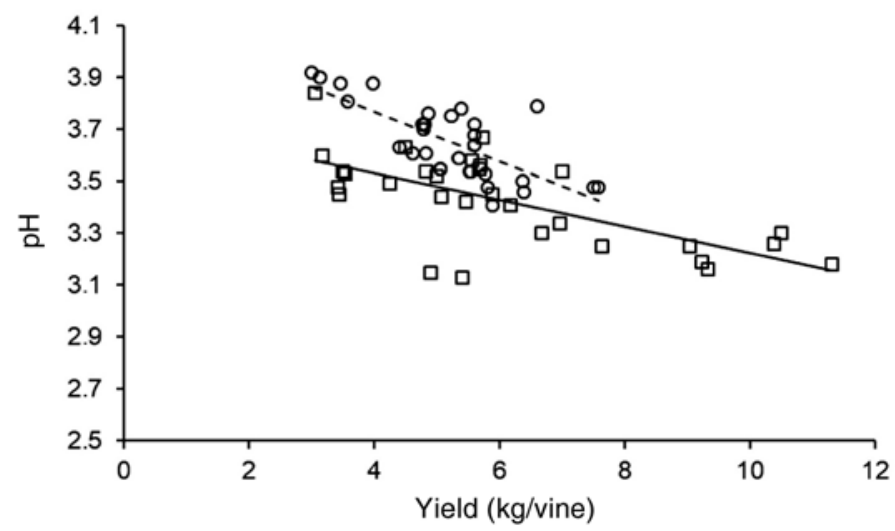

Figure 3 Influence of the site on the relation between yield and $\mathrm{pH}$ of Syrah wines. Data represent single treatment (pruning system $\times$ organic amendment $\times$ site) averages and data were pooled over repetitions: $\square$-Quinta do Côro (QC); ○-Quinta do Gradil (QG). Regression equations: $\mathrm{y}=-0.051 \mathrm{x}+3.73, \mathrm{r}^{2}=0.45, p=0.0001(\mathrm{QC})$; $y=-0.097 x+4.16, r^{2}=0.54, p<0.0001(Q G)$

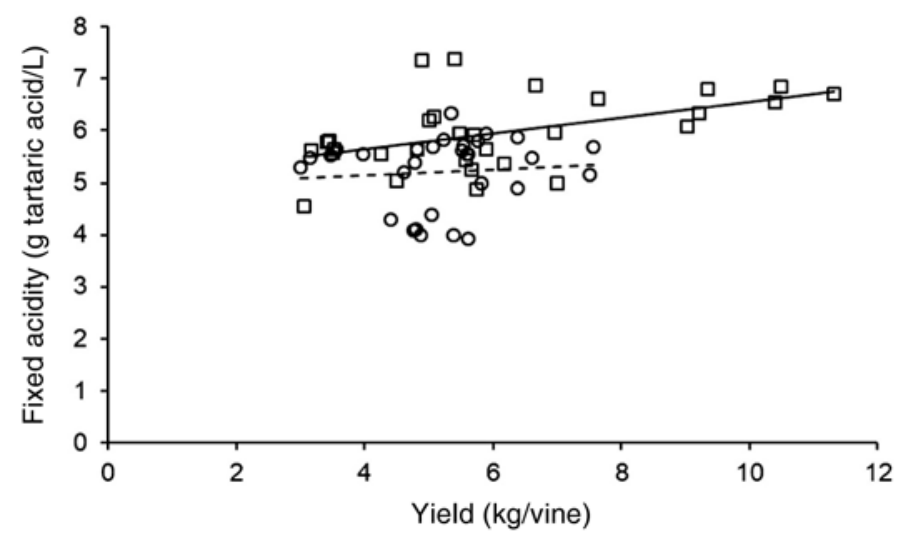

Figure 4 Influence of the site on the relation between yield and fixed acidity of Syrah wines. Data represent single treatment (pruning system $\times$ organic amendment $\times$ site) averages and data were pooled over repetitions: $\square$-Quinta do Côro (QC); O - Quinta do Gradil (QG). Regression equations:

$y=-0.152 x+3.73, r^{2}=0.241, p=0.0059(Q C) ;$

$y=-0.056 x+4.92, r^{2}=0.008, p=0.6342(Q G)$. 
(11.8 a.u.). Color hue was not significantly affected by organic amendments, and the interaction between pruning and organic amendments was never significant.

The effect of pruning system on total phenols is significant only in 2014, with lower values in MEC (11\% less). In the other two years, there was also a tendency for lower values in MEC. For tannin power, MEC treatments led to a decrease in this variable in 2014 and 2015 (32\% and 15\% less, respectively), although in 2015 the difference was not significant in the QG experimental site (Supplemental Table 4).

The organic amendments affected more of the total phenols concentration than the tannin power because in respect to total phenols, the differences were significant in 2014 and 2015 and the results trend was similar every year with higher values in Ctrl and Bioc, followed by MSWC and Manure, and with Sludge presenting the lowest total phenol values. In tannin power the results were significant only in 2015 with a reduction of this variable with soil organic amending, especially with Sludge.

The interaction of pruning system with organic amendments was not significant in any of the variables related to phenolic composition.

Total anthocyanins (Table 3 and Supplemental Table 5) were significantly higher in MAN wines in 2014 and 2015, even if in 2015 the differences were significant only in QC (Supplemental Table 4). Regarding polymerized pigments and polymerization index (Table 3 and Supplemental Table 5), in a global analysis, neither of these variables were significantly affected by the pruning system.

The organic amendments influenced total anthocyanins in 2013 and 2015. Wine from Sludge treatments had the lowest values of total anthocyanins (339 and $225 \mathrm{mg} / \mathrm{L}$ ), and those from Ctrl had the highest (481 and $402 \mathrm{mg} / \mathrm{L}$ ); intermediate levels were observed in Bioc, MSWC, and Manure.

Total and polymerized pigments were significantly influenced by the different amendments only in 2015. Regarding the polymerization index, significant differences occurred only in 2014, with higher values of this variable in Bioc (10.2\%).

The interaction between pruning system and organic amendments was never significant.

Both total anthocyanins and pigments had a negative relationship with yield (Figure 5 and Supplemental Figure 1). However, the relationship tended to be more negative in QG when compared to QC.

Total phenols had a negative relationship with yield (Supplemental Figure 2), and tannin power also had a negative relationship with yield in QC (Figure 6). However, in QG, a weak relationship was observed, with no differences in tannin power through a noteworthy range of yields.

Descriptive sensory analysis. The main sensory attributes of the wines (fruity, floral aromas and aroma balance, body astringency, and "global appreciation") from the different treatments are presented in Table 4 (other parameters are presented in Supplemental Tables 6 to 11).

Wines from MEC were, tendentially less red and in the last year, more violet than those from MAN. Concerning the descriptors used by the tasters to characterize the aroma of wines from different pruning systems, there were no differences between pruning systems, except for jam aroma, in 2014 (Supplemental Table 7), which was higher in MAN. Conversely, there were no differences on the aroma intensity, while the aroma balance tended to be lower in MEC. In 2015, no

Table 2 Effects of pruning system, organic amendment, and site on chromatic characteristics and phenolic composition of wine. a.u., absorbance units; NTU, nephelometric turbidity units.

\begin{tabular}{|c|c|c|c|c|c|c|c|c|c|c|c|c|}
\hline \multirow[b]{2}{*}{ Treatment $^{\mathrm{a}}$} & \multicolumn{3}{|c|}{ Color intensity (a.u.) } & \multicolumn{3}{|c|}{ Color hue } & \multicolumn{3}{|c|}{ Total phenols (a.u.) } & \multicolumn{3}{|c|}{$\begin{array}{c}\text { Tannin power } \\
\text { (NTU/mL) }\end{array}$} \\
\hline & 2013 & 2014 & 2015 & 2013 & 2014 & 2015 & 2013 & 2014 & 2015 & 2013 & 2014 & 2015 \\
\hline MAN & 12.6 & 10.0 & 9.0 & 0.639 & $0.626 a^{b}$ & 0.595 & 53.0 & $50.5 \mathrm{a}$ & 45.0 & 208 & $175 \mathrm{a}$ & $172 \mathrm{a}$ \\
\hline MEC & 11.1 & 10.2 & 9.9 & 0.609 & $0.558 \mathrm{~b}$ & 0.582 & 52.3 & $45.0 \mathrm{~b}$ & 43.6 & 199 & $120 \mathrm{~b}$ & $147 \mathrm{~b}$ \\
\hline Pruning effect & n.s. & n.s. & n.s. & n.s. & $* *$ & n.s. & n.s. & * & n.s. & n.s. & ** & ** \\
\hline Ctrl & 15.4 & 11.3 & $11.8 \mathrm{a}$ & 0.578 & 0.588 & 0.590 & 59.7 & $50.9 a b$ & $52.1 \mathrm{a}$ & 211 & 159 & $205 \mathrm{a}$ \\
\hline Bioc & 13.5 & 12.0 & $10.3 a b$ & 0.597 & 0.577 & 0.543 & 53.1 & $51.6 \mathrm{a}$ & $47.7 \mathrm{ab}$ & 201 & 139 & $186 a b$ \\
\hline MSWC & 11.2 & 9.5 & $8.9 a b$ & 0.634 & 0.593 & 0.611 & 52.8 & $48.0 \mathrm{ab}$ & $43.9 \mathrm{~b}$ & 204 & 155 & $155 \mathrm{c}$ \\
\hline Manure & 8.7 & 9.3 & $9.9 a b$ & 0.673 & 0.606 & 0.601 & 50.3 & $47.6 a b$ & $44.5 \mathrm{~b}$ & 188 & 142 & $156 \mathrm{bc}$ \\
\hline Sludge & 10.2 & 8.5 & $6.4 \mathrm{~b}$ & 0.636 & 0.597 & 0.597 & 47.5 & $40.8 \mathrm{~b}$ & $33.2 \mathrm{c}$ & 215 & 141 & $96 \mathrm{~d}$ \\
\hline Amend. effect & n.s. & n.s. & * & n.s. & n.s. & n.s. & n.s. & * & ** & n.s. & n.s. & $* * *$ \\
\hline QC & $17.7 \mathrm{a}$ & $12.9 \mathrm{a}$ & 9.7 & 0.607 & $0.528 \mathrm{~b}$ & 0.582 & $66.0 \mathrm{a}$ & $50.1 \mathrm{a}$ & $42.5 \mathrm{~b}$ & $264 a$ & $166 \mathrm{a}$ & $153 \mathrm{~b}$ \\
\hline QG & $6.0 \mathrm{~b}$ & $7.3 \mathrm{~b}$ & 9.3 & 0.640 & 0.657 a & 0.594 & $39.3 \mathrm{~b}$ & $45.4 \mathrm{~b}$ & $46.1 \mathrm{a}$ & $143 \mathrm{~b}$ & $129 b$ & $166 \mathrm{a}$ \\
\hline Site effect & ** & ** & n.s. & n.s. & $* \star *$ & n.s. & ** & * & * & $* * *$ & * & * \\
\hline \multicolumn{13}{|l|}{ Interactions } \\
\hline Prun $\times$ Amend & n.s. & n.s. & n.s. & n.s. & n.s. & n.s. & n.s. & n.s. & n.s. & n.s. & n.s. & n.s. \\
\hline Prun $\times$ Site & n.s. & n.s. & n.s. & * & * & n.s. & n.s. & n.s. & ** & n.s. & n.s. & * \\
\hline Amend $\times$ Site & n.s. & n.s. & n.s. & n.s. & n.s. & n.s. & n.s. & n.s. & n.s. & n.s. & n.s. & n.s. \\
\hline
\end{tabular}

aPruning system: hand pruning (MAN) and mechanical pruning (MEC). Organic amendments: control (Ctrl), biochar (Bioc), municipal solid waste compost (MSWC), cattle manure (Manure), and sewage sludge (Sludge). Site: Quinta do Côro (QC), Quinta do Gradil (QG).

bStatistical significance of the effects of pruning system, organic amendment, experimental site, and their interactions: n.s., not significant at $p<0.05$ level by $\mathrm{F}$ test; ${ }^{*},{ }^{* *},{ }^{* *}$ significant at $p<0.05,0.01$, and 0.001 , respectively. Within each column and for each factor, mean values followed by a different letter are significantly different at $p<0.05$ by Tukey's honest significant difference test. 




differences were found between tastes of the pruning systems, while in the first two years, wines from MEC were less bodied and balanced. In 2013, MEC wines were also less astringent and persistent. Finally, in 2013 and 2014, wines from MEC had lower global appreciation (8 and 10\%, respectively).

When comparing organic amendments, the differences in red color were not substantial, with Manure and Sludge being significantly lower than the other treatments in 2013 and 2014 , respectively. However, violet color differences were higher, with Sludge wines being consistently less violet, followed by Manure and MSWC. Except for 2013, Bioc did not significantly differ from $\mathrm{Ctrl}$, which had the highest values of violet color.

Concerning the aroma, except for the 2015 MSWC wineswhich were less balanced than those from Ctrl-the only treatment that differed significantly from Ctrl was Sludge. When compared to the Ctrl, the 2013 Sludge wines were less intense and with lower levels of jam aroma, while in 2014,

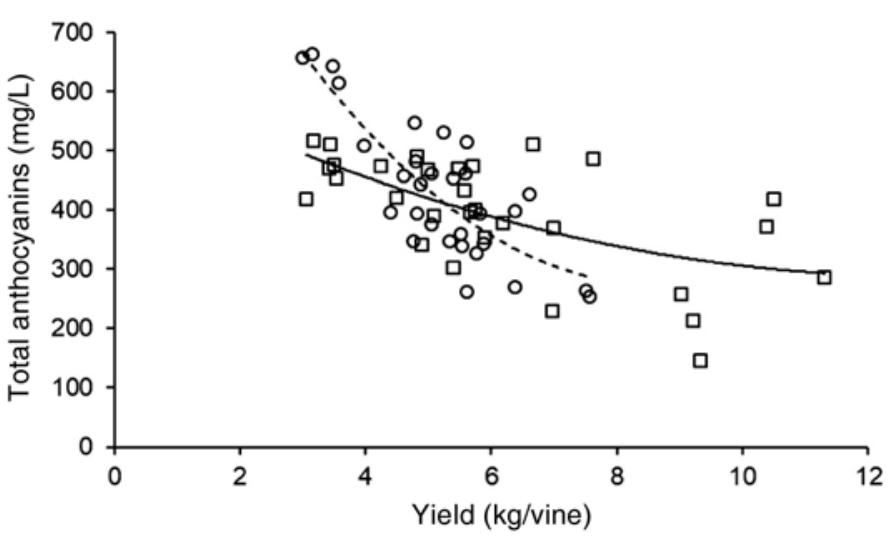

Figure 5 Influence of the site on the relation between yield and total anthocyanins of Syrah wines. Data represent single treatment (pruning system $\times$ organic amendment $\times$ site) averages and data were pooled over repetitions: $\square$ - Quinta do Côro (QC); $\bigcirc$ - Quinta do Gradil (QG). Regression equations:

$y=2.09 x^{2}-54.24 x+638.9, r^{2}=0.39, p=0.0004(Q C)$;

$y=12.75 x^{2}-217.32 x+1201.6, r^{2}=0.68, p<0.0001(Q G)$.



Figure 6 Influence of the site on the relation between yield and tannin power of Syrah wines. Data represent single treatment (pruning system $\times$ organic amendment $\times$ site) averages and data were pooled over repetitions: $\square$-Quinta do Côro (QC); ○ - Quinta do Gradil (QG). NTU, nephelometric turbidity units. Regression equations:

$y=1.86 x^{2}-50.63 x+423.53, r^{2}=0.39, p<0.0001(Q C) ;$

$y=0.14 x^{2}-5.91 x+173.10, r^{2}=0.02, p=0.4286(Q G)$. 


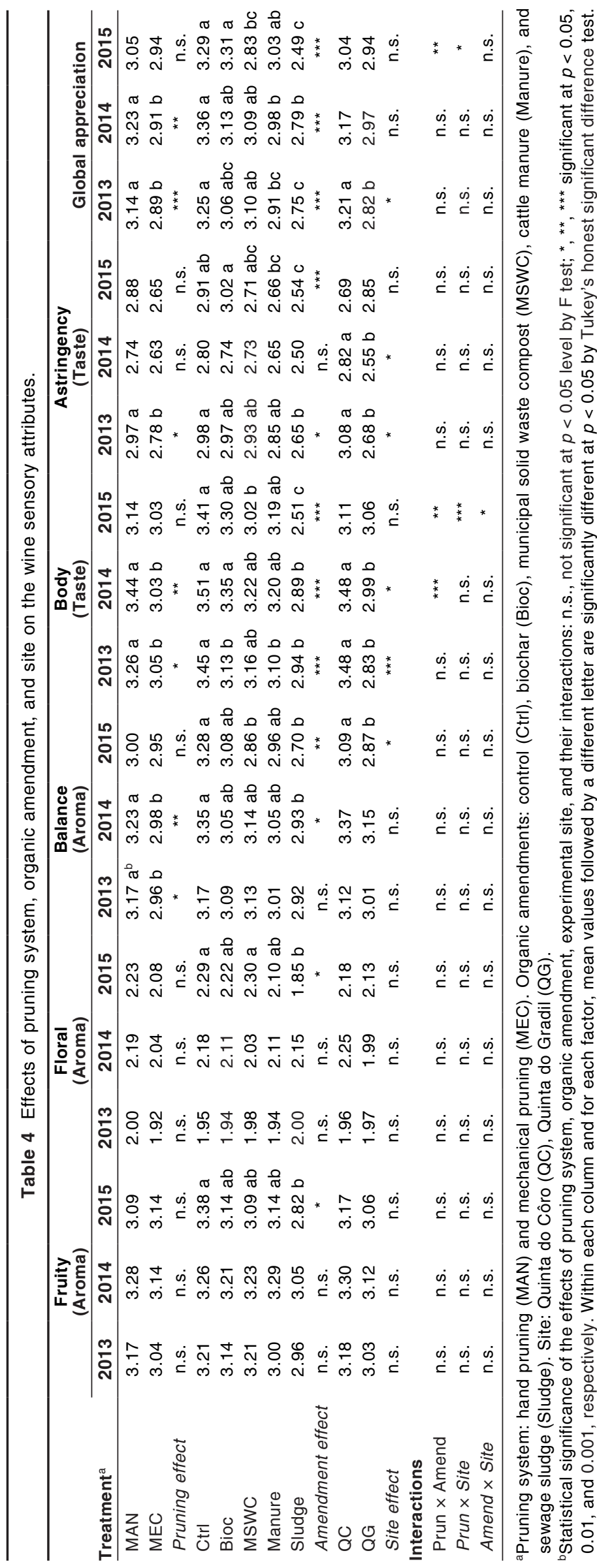

they were less balanced. In 2015, wines from Sludge were less intense and balanced, with lower levels of fruit, floral, and jam aromas.

The wines from Sludge were the less bodied of all organic amendment treatments, differing significantly from $\mathrm{Ctrl}$ in all the evaluated vintages. The effect of this factor on bitterness and astringency of wines was not always significant, but wines from Sludge showed to be the less astringent wines, followed by MSWC and Manure. Tasters found no significant differences in the acidity of wines from different organic amendments, while persistency and balance were always affected. In the first two years, Sludge wines were the least persistent and balanced and the only wines that significantly differed from Ctrl, while in 2015 MSWC had a similar behavior. The interaction between pruning system and organic amendment effects on body (Supplemental Table 12) shows that there were no significant differences between MAN/Bioc, $\mathrm{MAN} / \mathrm{Ctrl}, \mathrm{MEC} / \mathrm{Bioc}$, and $\mathrm{MEC} / \mathrm{Ctrl}$ treatments, and that wines from MEC/Sludge were the less bodied.

Tasters consistently classified Sludge wines with the lowest "global appreciation" score (with an average of 2.68). MSWC and Manure had intermediate scores (with averages of 3.01 and 2.97, respectively) and did not significantly differ from each other in any of the analyzed years. The Ctrl and Bioc had the highest scores in global appreciation and a similar performance (with averages of 3.30 and 3.17, respectively). The interaction between pruning system and organic amendment effects on global appreciation (Supplemental Table 12) shows that there were no significant differences between MAN/Bioc, $\mathrm{MAN} / \mathrm{Ctrl}, \mathrm{MEC} / \mathrm{Bioc}$, and $\mathrm{MEC} / \mathrm{Ctrl}$ treatments, and that wines from MAN/Sludge and MEC/Sludge had the lowest global appreciation.

The relation between yield and global appreciation of wines is presented in Figure 7. The relationship between these variables is weak when yield is lower than 6 and $8 \mathrm{~kg} /$ vine in QG and QC, respectively, and no decrease in quality is observed with the increase in yield. When yield exceeds



Figure 7 Influence of the site on the relation between yield and global appreciation of Syrah wines. Data represent single treatment (pruning system $\times$ organic amendment $\times$ site) averages and data were pooled over repetitions: $\square$-Quinta do Côro (QC); $\bigcirc$ - Quinta do Gradil (QG). Regression equations:

$\mathrm{y}=-0.019 \mathrm{x}^{2}+0.156 \mathrm{x}+2.926, \mathrm{r}^{2}=0.44, p=0.0004(\mathrm{QC})$

$y=-0.047 x^{2}+0.313 x+2.609, r^{2}=0.38, p=0.0010(Q G)$. 
the referred thresholds, there is a tendency for lower global appreciation scores in wines.

\section{Discussion}

Classical chemical parameters. Some physicochemical characteristics of wines (Table 1) were significantly affected by the pruning system and the organic amendments. Overall, the alcoholic strength of wine was negatively affected by MEC in all three years, as observed by Reynolds (1988) and Pérez-Bermúdez et al. (2015). However, as shown in Figure 2 , there is a high association between the TSS decrease and the yield increase that MEC induces, particularly with the organic amendments-Manure, MSWC, and Sludge - which provide more principal macronutrients and increase the total dry mass production (Botelho et al. 2020). When the yields are similar, there are no considerable TSS differences between MEC and MAN treatments (Botelho et al. 2021).

According to Clingeleffer (1988), Spayd et al. (1994), and Wessner and Kurtural (2013), higher yields and the associated lower leaf area to fruit ratios delay ripening. In the case of QC, some delay of the harvest is not problematic because September is usually a dry month in the Tejo wine region (IPMA 2020). In QG, however, that can be a problem because the harvest will be postponed until October, when rainfall usually occurs in the Lisboa wine region (IPMA 2020), and Botrytis cinerea Pers. infections are highly probable (Elmer and Michailides 2007). When comparing the relationship between wine alcohol content and yield in both sites, it is noteworthy that the regression lines have similar slopes, but for the same level of production, QG wines had lower alcohol content. The higher alcoholic content in QC is associated with the higher average temperatures observed in this site during all three years (Botelho et al. 2020). These results are in accordance with those of Jackson and Lombard (1993).

In addition to the reduction of alcoholic strength caused by the increase of productivity, there is a significant tendency for wines of Sludge treatment to have lower alcohol content when compared to the other organic amendments - even with similar yields. Hilbert et al. (2003) and Delgado et al. (2004) also observed a delay in ripening due to high $\mathrm{N}$ supply, even without an increase in productivity or a decrease in leaf to fruit ratio. Delgado et al. (2004) and Korboulewsky et al. (2004) attribute the decrease in wine alcohol content to the increase of vine vigor, caused by high $\mathrm{N}$ supply, which changes the balance in carbon partitioning, favoring vegetative growth in detriment of reproductive growth. In our study, vine vigor (as also reported by Botelho et al. 2020) tended to be higher in Sludge, when compared to Ctrl and Bioc, and is likely to be the cause of the inferior alcoholic strength value observed in the corresponding wines.

The wine $\mathrm{pH}$ showed a clear tendency for decrease with MEC, which was also observed by Morris and Cawthon (1981) and Holt et al. (2008). The reduction of $\mathrm{pH}$ in MEC is probably related to the referred delay in ripening and/or to a lower $\mathrm{K}$ content, which was associated with a growth induced dilution. A negative relationship between yield and wine $\mathrm{pH}$ was observed, with QG having a stronger decline when compared to QC. According to Jackson and Lombard (1993) there is a negative relationship between $\mathrm{pH}$ and crop load, which was always higher in MEC and increased with yield growth (Botelho et al. 2020). Surprisingly, the wine $\mathrm{pH}$ was lower in QC when compared to QG, which was not expected because the average temperatures in this site were higher, and a higher malic acid degradation would be expected (Keller 2010). However, the wine K content was significantly higher in QG (Table 1), which led to a higher precipitation of tartaric acid as potassium hydrogen tartrate (Ribéreau-Gayon et al. 2000) and consequently, to a higher pH (Conradie and Sayman 1989).

Usually, grape total acidity is not affected by mechanical pruning (Clingeleffer 1988, Holt et al. 2008), as occurred in our study (as also reported by Botelho et al. 2021). However, although TA of must was not significantly different because of pruning system, in wine, total and fixed acidity were both lower in MAN. These differences are probably related to the differences found in $\mathrm{K}$ concentration between treatments. As already stated, the lower concentration of K in MEC wines led to less precipitation of tartaric acid as potassium hydrogen tartrate (Ribéreau-Gayon et al. 2000), and consequently, higher concentrations of this acid remained in the wines from these treatments.

Although slight significant differences were observed in 2014 in must pH, among different organic amendments, they are not relevant in a practical point of view. Thus, throughout this study, organic amendments affected neither $\mathrm{pH}$ nor TA of must and wine. Identical results were obtained by Morlat and Symoneaux (2008).

Wine FA had a weak correlation with yield in both sites, as observed by González-Flor et al. (2014). The present results show that FA is more related to the site, with QG having less acidity than QC due to the K content, than to yield.

Color parameters and phenolic compounds. Concerning color (Table 3 ) during this study, the pruning system had low influence on color intensity and color hue of wines, as observed by Keller and Mills (2007). Although pruning did not affect wine color intensity, the total anthocyanin content (Table 3) was significantly lower in MEC. This is contrary to what was reported by Holt et al. (2008) and Wessner and Kurtural (2013) but is in accordance with what Poni et al. (2004) and Main and Morris (2008) observed with minimal pruning. The lower anthocyanin content in MEC may be related to the delay in sugar accumulation-essential in the regulation of color development (Castellarin et al. 2011) — which in this case, overlapped the effect of the higher skin-to-flesh ratio of MEC berries (Botelho et al. 2020). However, because $\mathrm{pH}$ in MEC wines was lower than in MAN, the anthocyanin ionization index was higher and more anthocyanin molecules were in the red-colored form of flavylium cation (Somers and Evans 1977, Ribéreau-Gayon et al. 2000), compensating for their lower content and maintaining wine color intensity.

Total pigments were significantly lower in MEC in 2014 and 2015, which is in accordance with the difference observed in total anthocyanin content and is probably a consequence of the yield increase promoted by MEC that reduced the leaf area to production ratio (Botelho et al. 2020). Striegler and 
Lake (2002) also found a significant decrease in total pigments with machine pruning, while Main and Morris (2008) found no differences. Because in 2014 the polymerization index was not different between pruning treatments, MAN had more polymerized pigments than MEC. In 2015, although total pigments were higher in MAN, the polymerization index was higher in MEC and there were no significant differences in polymerized pigment content. Thus, although there is a tendency for lower total pigment content in MEC, in some years, when the polymerization index is higher in this pruning system, the result is an identical level of polymerized pigments, which when compared to anthocyanins, are much less sensitive to changes in $\mathrm{pH}$ and are quite resistant to decolorization by $\mathrm{SO}_{2}$ (Somers 1971).

Concerning the effect of organic amendments on color (although the differences in color intensity between treatments are significant only in 2015), there is always a tendency for higher color intensity in Ctrl and lower in MSWC, Manure, and Sludge. This trend is corroborated by the reduction observed in total anthocyanin content, as well as in total pigments. The higher yield observed in these treatments and the consequent delay in ripening may be related to the decrease in anthocyanin content and color intensity, as already stated. However, according to Hilbert et al. (2003), a high N supply interferes with the metabolic pathway of anthocyanins, delaying quantitative and qualitative biosynthesis, and enhances their degradation in the final steps of berry maturation. So both of these two facts may occur at the lower color intensity anthocyanin content and total pigments in MSWC, Manure, and especially in Sludge. In Sludge treatment, the high P supply can also be in the origin of the lower total anthocyanin content, because when in excess, P may inhibit the induction of phenylalanine ammonia-lyase and chalcone synthase activity, leading to a reduction of anthocyanin content of berries (Kakegawa et al. 1995).

A negative relationship between wine total anthocyanins and yield was observed (Figure 5). A similar trend was observed for total pigments (Supplemental Figure 1). This decrease in total anthocyanins is probably related to grape sugar content, which also decreased with yield. The relationship between sugar and anthocyanin accumulation was demonstrated by Pirie and Mullins (1976); Yokotsuka et al. (1999) also found a positive correlation between grape sugar content and total anthocyanins and pigments.

Wine total phenol content (Table 4) was slightly reduced by MEC only in one of the four years in the study (2014), while in the other years, no significant differences were observed between pruning systems. Pérez-Bermúdez et al. (2015) also found a reduction in total phenol content in mechanical pruning only in one of three years of the trial, while Wessner and Kurtural (2013) found no differences between pruning systems, and Holt et al. (2008) observed higher total phenol levels in machine pruned treatments.

The organic amendments significantly affected total phenols in 2014 and in 2015. In both years, Ctrl and Bioc were the treatments with the highest value of this variable and Sludge was the one with the lowest, while MSWC and Manure pre- sented intermediate values. Delgado et al. (2004) reported a reduction in total phenol content with the application of $\mathrm{N}$ to soil, so the observed results are probably related to the $\mathrm{N}$ supplied by Sludge, MSWC, and Manure. Delgado et al. (2004) also state that total phenol content decreases with the application of K. MSWC and Manure provide less N and more K than Sludge and perhaps because of this, total phenol content is higher than in Sludge wines.

Total phenols were negatively correlated with yield (Supplemental Figure 2). This reduction in total phenols may be related to a growth-induced dilution phenomenon, due to the yield increase and/or to a decrease in grape sugar content, as observed by Yokotsuka et al. (1999).

Tannin power, which is defined as the tannin specific activity of the wine (De Freitas and Mateus 2002), is used to characterize the reactivity of polyphenols toward proteins (De Freitas and Mateus 2002) and has a positive correlation with the wine astringency (Mateus at al. 2004). The observed lower tannin power in MEC wines is indicative of a lower astringency perception in our mouths and is consistent with the results obtained concerning the wine total phenols. The same trend is observed with organic amendments, because significant differences in tannin power were observed only in 2015, which is also the year when wine total phenols had more differences among organic amendments.

Concerning the relationship between tannin power and yield (Figure 6), a negative correlation was found in QC, in line with the total phenols behavior. However, in QG, tannin power had a weak correlation with yield, although total phenols were negatively correlated with yield. Tannin power levels are more resistant to yield fluctuations; the reason for this requires further study.

Descriptive sensory analysis. The sensory analysis (Table 4) shows that the pruning system tends to induce significant differences in less wine quality parameters than organic amendments.

MEC wine color (Supplemental Tables 3 to 5) has a tendency to be less red and, in some years, more violet, corroborating the results of color hue and showing a younger color. Throughout this study, no differences were found in the descriptors used to characterize the wine aroma or in the aroma intensity (Supplemental Tables 3 to 5) between pruning systems. However, the aroma balance was tendentially reduced by mechanical pruning. Sims et al. (1990) observed lower aroma intensity in wines obtained from mechanically pruned Muscadine grapes, while Reynolds (1988) found no differences in wine aroma with mechanical box pruning.

Wine taste was also influenced by pruning system, with MEC tendentially reducing body and balance (Supplemental Tables 3 to 5) and in a lesser extent, astringency and persistence (Supplemental Tables 3 to 5). When compared to the spur-pruned vines, Morris and Cawthon (1981) found a decrease in the score given by tasters to the taste of wines from mechanically pruned vines, even with lower yields. On the other hand, Reynolds (1988) found no differences in taste between pruning systems with significantly higher yields in mechanical pruning. It is interesting to note that the 
astringency results given by tasters are in accordance with those obtained for tannin power (Table 4). Tannin power is a chemical approach to what can be the astringency perception of a wine by a taster.

Regarding "global appreciation", tasters found significant differences between pruning systems, with MEC wines presenting lower values in two of the three years. However, even when significant, the differences were low ( 0.25 points in 2013 and 0.32 points in 2014); when comparing the pruning system in the same organic amendment, year, and trial field, the quality of MEC wines was higher in several instances, especially in Ctrl where $67 \%$ of the time, MEC wines had higher global appreciation than MAN (Supplemental Tables 9 to 11). Holt et al. (2008) also found small but significant differences in the quality score of Cabernet Sauvignon wines in two of three years of comparison between hand and mechanical pruning (an average difference of 0.30 points in a 20-point scale). Morris and Cawthon (1981) found larger and more significant differences in the overall quality of wines from mechanical and hand pruning.

During this study, the organic amendments-especially Sludge-decreased wine color. In terms of aroma, Sludge was the only treatment that presented significant differences when compared to Ctrl. Wines from Sludge treatment had less intense and less balanced aroma with lower levels of fruit, flowers, and jam. In terms of palate, wines from Sludge also obtained the lowest scores with less body, astringency, persistence, and balance. The high levels of N supplied by Sludge may be the origin of this result, as reported by Treeby et al. (2000) who, working with Syrah, observed a decrease in wine color, palate intensity, and final wine score with the application of $\mathrm{N}$ to the vineyard soil. Korboulewsky et al. (2004) also reported that wines from high rates of sewage sludge compost have low olfactory quality and less overall wine quality. A likely explanation for these observations is that $\mathrm{N}$ application in the vineyard increases the assimilable amino $\mathrm{N}$ concentration of musts, which shortens fermentation and may reduce the wine contact with skins (Bell and Henschke 2005). However, in the present study, although the juice $\mathrm{N}$ content was higher in Sludge, the maceration time and temperature were equal between all the treatments and for all years and locales. Thus, the reduced quality in Sludge wines is probably related to the several effects that $\mathrm{N}$ triggers in the vine that result in grapes and wines with different sensory profiles.

Regarding the Bioc, MSWC, and Manure effects on sensory attributes of wines, these treatments tend to have an intermediate behavior between Ctrl and Sludge and do not differ significantly from Ctrl throughout this study. However, in terms of "global appreciation", MSWC is significantly lower from Ctrl in one year, while Manure is lower in two of the three years. In a global analysis, MSWC is not significantly different from Ctrl, while Manure is. Although the yields of these two treatments are similar, Manure has more available $\mathrm{N}$ than MSWC and, as discussed previously, this may be the reason for the differences observed.

As already stated, yield had a negative relationship to grape TSS. However, the relationship between yield and glob- al appreciation is weak, especially when productivity is below $6 \mathrm{~kg} / \mathrm{vine}$ in QG and $8 \mathrm{~kg} / \mathrm{vine}$ in QC (Figure 7). Above these thresholds, a tendency for lower quality levels was observed, but below them there was no relationship between yield and global appreciation; MAN and MEC wines had similar global appreciation.

It is also evident that the lower global appreciation observed in MEC is associated with the high yields that this pruning system achieved, when it was combined with MSWC, Manure, and Sludge. However, even when combined with the referred organic amendments, if yield did not exceed the already stated thresholds, tasters did not penalize these wines (Figure 7).

The relationship between wine global appreciation and yield is more negatively correlated in QG than in QC. The threshold above which the tasters penalized wine quality was lower in QG when compared to QC. To the best of our knowledge, there are no studies comparing the relationship between wine quality and yield in different climates. However, the higher radiation and temperature availability in QC probably led to higher photosynthetic and metabolic activities (Jackson and Lombard 1993), allowing a higher amount of fruit to correctly ripen.

\section{Conclusions}

Mechanical pruning associated with soil organic amending significantly reduced wines' alcoholic strength. This reduction is related to a delay in grape sugar accumulation due to an increase in productivity. In warm regions, this fact is not a problem because harvest can be delayed with no threat of bunch rot. In cooler areas, however, it must be considered that the application of organic amendments in high amounts may increase productivity, but may also delay harvest to periods when autumn precipitation can trigger $B$. cinerea Pers. infections.

Mechanical pruning tended to reduce $\mathrm{pH}$ and increase total and fixed acidity, while the organic amendments had no effects on these parameters. Mechanical pruning affected wine color components but not color intensity, had few effects on wine total phenols, and reduced tannin power (astringency potential). Conversely, organic amendments induced a significant reduction in color components as well as in color intensity, total phenols, and tannin power.

MSWC had similar effects, when compared to Manure. Thus, it seems an interesting alternative to Manure and a good destination for these residues from human settlements. Sludge originated wines with inferior quality, but because of the high productivity induced, it can be an interesting alternative for the production of cheaper wines which can be considered entry level wines in the portfolio of a wine company.

Yield had no relationship with FA, but a negative one with several other assessed variables such as $\mathrm{pH}$, total anthocyanins, total pigments, total phenols, and tannin power. Mechanical pruning significantly reduced wine balance, body, and global appreciation. However, when yield was below 6 $\mathrm{kg} /$ vine in QG (cooler climate) and $8 \mathrm{~kg} / \mathrm{vine}$ in QC (warmer climate) mechanical pruning had few effects on wine sensory 
analysis. Above that threshold, which was exceeded only in some years and by treatments with mechanical pruning associated with soil organic amending, there was a tendency for the production of wines with lower global appreciation. Therefore, the results of this study conclude that mechanical pruning associated with the organic amending of soil is a powerful tool to regulate vine yield and to produce a range of wines with different quality.

The valorization of human residues is a key challenge in today's economy. This work shows that the use of nonconventional organic amendments is a powerful tool to increase vineyard profitability and a step toward a more circular economy.

\section{Literature Cited}

Baronti S, Vaccaria FP, Miglietta F, Calzolari C, Lugato E, Orlandini S, Pini R, Zulian C and Genesio L. 2014. Impact of biochar application on plant water relations in Vitis vinifera (L.). Eur J Agron 53:38-44.

Bell SJ and Henschke PA. 2005. Implications of nitrogen nutrition for grapes, fermentation and wine. Aust J Grape Wine Res 11:242-295.

Botelho M, Cruz A, Ricardo-da-Silva J, de Castro R and Ribeiro H. 2020. Mechanical pruning and soil fertilization with distinct organic amendments in vineyards of Syrah: Effects on vegetative and reproductive growth. Agronomy 10:1090.

Botelho M, Ribeiro H, Cruz A, Duarte DF, Faria DL, de Castro R and Ricardo-da-Silva J. 2021. Mechanical pruning and soil organic amendments in vineyards of Syrah: Effects on grape composition. OENO One 55:267-277.

Castellarin SD, Gambetta GA, Wada H, Shackel KA and Matthews MA. 2011. Fruit ripening in Vitis vinifera: Spatiotemporal relationships among turgor, sugar accumulation, and anthocyanin biosynthesis. J Exp Bot 62:4345-4354.

Clingeleffer PR. 1988. Response of Riesling clones to mechanical hedging and minimal pruning of cordon trained vines (MPCT)implications for clonal selection. Vitis 27:87-93.

Conradie WJ and Saayman D. 1989. Effects of long-term nitrogen, phosphorus, and potassium fertilization on Chenin blanc vines. II. Leaf analyses and grape composition. Am J Enol Vitic 40:91-98.

Correia C. 2014. Efeitos da poda manual e mecânica e da aplicação de diferentes correctivos orgânicos ao solo na composição química e análise sensorial de uvas e vinhos da casta Shiraz nas regiões do Tejo e de Lisboa. Master Thesis, Instituto Superior de Agronomia, Universidade de Lisboa, Lisboa.

De Freitas V and Mateus N. 2002. Nephelometric study of salivary protein-tannin aggregates. J Sci Food Agric 82:113-119.

Delgado R, Martín P, Álamo M and González MR. 2004. Changes in the phenolic composition of grape berries during ripening in relation to vineyard nitrogen and potassium fertilization rates. J Sci Food Agric 84:623-630.

Egnér H, Riehm H and Domingo WR. 1960. Untersuchhungen uber die chemische boden: Analyse als grundlage fur die beurteilung der nahrstoffzustandes der boden. II. Chemique extractions, methoden zur phosphor, und kalium-bestimmung. Kungl Lantbrukshögskolans Ann 26:199-215

Elmer PAG and Michailides TJ. 2007. Epidemiology of Botrytis cinerea in orchard and vine crops. In Botrytis: Biology, Pathology and Control. Elad Y et al. (eds.), pp. 243-262. Springer, Dordrecht, The Netherlands.

Fangueiro D, Ribeiro HM, Vasconcelos E, Coutinho J and Cabral F. 2012. Influence of animal slurries composition and relative particle size fractions on the $\mathrm{C}$ and $\mathrm{N}$ mineralization following soil incorporation. Biomass Bioenerg 47:50-61.
Freeman BM and Kliewer WM. 1983. Effect of irrigation, crop level and potassium fertilization on Carignan vines. II. Grape and wine quality. Am J Enol Vitic 34:197-207.

Gatti M, Schippa M, Garavani A, Squeri C, Frioni T, Dosso P and Poni S. 2020. High potential of variable rate fertilization combined with a controlled released nitrogen form at affecting cv. Barbera vines behavior. Eur J Agron 112:125949.

González-Flor C, Serrano L, Gorchs G and Pons JM. 2014. Assessment of grape yield and composition using reflectance-based indices in rainfed vineyards. Agron J 106:1309-1316.

Hilbert G, Soyer JP, Molot C, Giraund J, Milin S and Gaudillere JP. 2003. Effects of nitrogen supply on must quality and anthocyanin accumulation in berries of cv. Merlot. Vitis 42:69-76.

Holt HE, Francis IL, Field J, Herderich MJ and Iland PG. 2008. Relationships between wine phenolic composition and wine sensory properties for Cabernet Sauvignon (Vitis vinifera L.). Aust J Grape Wine Res 14:162-176.

Illera-Vives M, López-Fabal A, López-Mosquera ME and Ribeiro HM. 2015. Mineralization dynamics in soil fertilized with seaweed-fish waste compost. J Sci Food Agric 95:3047-3054.

IPMA. 2020. Available online: http://www.ipma.pt/pt/oclima/normais. clima/ (accessed 2 May 2020).

ISO 3591:1977. Sensory analysis-Apparatus-Wine-tasting glass. (International Organization for Standardization) https://www.iso. org/standard/9002.html.

ISO 8589:2007. Sensory analysis-General guidance for the design of test rooms. (International Organization for Standardization) https:// www.iso.org/standard/36385.html.

ISO 8586:2012. Sensory analysis-General guidelines for the selection, training and monitoring of selected assessors and expert sensory assessors. (International Organization for Standardization) https:// www.iso.org/standard/45352.html.

ISO 11132:2012. Sensory analysis-Methodology-Guidelines for monitoring the performance of a quantitative sensory panel. (International Organization for Standardization) https://www.iso.org/ standard/50124.html.

Jackson DI and Lombard PB. 1993. Environmental and management practices affecting grape composition and wine quality-A review. Am J Enol Vitic 44:409-430.

Jeffery S, Verheijen FGA, van der Velde M and Bastos AC. 2011. A quantitative review of the effects of biochar application to soils on crop productivity using meta-analysis. Agr Ecosyst Environ 144:175-187.

Kakegawa K, Suda J, Sugiyama M and Komamine A. 1995. Regulation of anthocyanin biosynthesis in cell suspension cultures of Vitis in relation to cell division. Physiol Plant 94:661-666.

Keller M. 2010. Managing grapevines to optimize fruit development in a challenging environment: A climate change primer for viticulturists. Aust J Grape Wine Res 16:56-69.

Keller M and Mills LJ. 2007. Effect of pruning on recovery and productivity of cold-injured Merlot grapevines. Am J Enol Vitic 58:351-357.

Korboulewsky N, Robles C and Garzino S. 2004. Effects of sewage sludge compost on volatile organic compounds of wine from Vitis vinifera cv. red Grenache. Am J Enol Vitic 55:412-416.

Lehmann J, Pereira da Silva J, Steiner C, Nehls T, Zech W and Glaser B. 2003. Nutrient availability and leaching in an archaeological Anthrosol and a Ferralsol of the Central Amazon basin: Fertilizer, manure and charcoal amendments. Plant Soil 249:343-357.

Main GL and Morris JR. 2008. Impact of pruning methods on yield components and juice and wine composition of Cynthiana grapes. Am J Enol Vitic 59:179-187. 
Mateus N, Pinto R, Ruão P and De Freitas V. 2004. Influence of the addition of grape seed procyanidins to Port wines in the resulting reactivity with human salivary proteins. Food Chem 84:195-200.

Messiga AJ, Gallant KS, Sharifi M, Hammermeister A, Fuller K, Tango $\mathrm{M}$ and Fillmore S. 2016. Grape yield and quality response to cover crops and amendments in a vineyard in Nova Scotia, Canada. Am J Enol Vitic 67:77-85.

Morlat R and Symoneaux R. 2008. Long-term additions of organic amendments in a Loire Valley vineyard on a calcareous sandy soil. III. effects on fruit composition and chemical and sensory characteristics of Cabernet franc Wine. Am J Enol Vitic 59:375-386.

Morris JR and Cawthon DL. 1981. Yield and quality response of Concord grapes (Vitis labrusca L.) to mechanized vine pruning. Am J Enol Vitic 32:280-282.

Mpelasoka BS, Schachtman DP, Treeby MT and Thomas MR. 2003. A review of potassium nutrition in grapevines with special emphasis on berry accumulation. Aust J Grape Wine Res 9:154-168.

OIV. 2021. Recueil des méthodes internationales d'analyse des vins et des môuts. Organisation International de la Vigne et du Vin, Paris.

Park JH, Choppala GK, Bolan NS, Chung JW and Chuasavathi T. 2011. Biochar reduces the bioavailability and phytotoxicity of heavy metals. Plant Soil 348:439.

Pérez-Bermúdez P, Olmo M, Gil J, Garciá-Ferriza L, Olmo C, Boluda $\mathrm{R}$ and Gavidia I. 2015. Effects of traditional and light pruning on viticultural and oenological performance of Bobal and Tempranillo vineyards. J Int Sci Vigne Vin 49:145-154.

Pinamonti F. 1998. Compost mulch effects on soil fertility, nutritional status and performance of grapevine. Nutr Cycl Agroecosys 51:239-248.

Pirie A and Mullins MG. 1976. Changes in anthocyanin and phenolics content of grapevine leaf and fruit tissues treated with sucrose, nitrate, and abscisic acid. Plant Physiol 58:468-472.

Poni S, Bernizzoni F, Presutto P and Rebucci B. 2004. Performance of Croatina under short-cane mechanical hedging: A successful case of adaptation. Am J Enol Vitic 55:379-388.

Reynolds AG. 1988. Response of Okanagan Riesling vines to training system and simulated mechanical pruning. Am J Enol Vitic 39:205-212.

Ribéreau-Gayon J, Peynaud E, Sudraud P and Ribéreau-Gayon P. 1982. Sciences et Techniques du Vin. I - Analyse et Contrôle des Vins. Dunod, Paris.

Ribéreau-Gayon P, Glories Y, Maujean A and Dubourdieu D. 2000. Handbook of Enology: Volume 2, The Chemistry of Wine Stabilisation and Treatments. John Wiley \& Sons Ltd, Chichester, UK.
Richards JR, Zhang H, Schroder JL, Hattey JA, Raun WR and Payton ME. 2011. Micronutrient availability as affected by the long-term application of phosphorus fertilizer and organic amendments. Soil Sci Soc Am J 75:927-939.

Sánchez-Monedero MA et al. 2019. Agronomic evaluation of biochar, compost and biochar-blended compost across different cropping systems: Perspective from the European Project FERTIPLUS. Agronomy 9:225.

Sims CA, Johnson RP and Bates RP. 1990. Effects of mechanical pruning on the yield and quality of Muscadine grapes. Am J Enol Vitic 41:273-276.

Somers TC. 1971. The polymeric nature of wine pigments. Phytochemistry 10:2175-2186.

Somers TC and Evans ME. 1977. Spectral evaluation of young red wines: Anthocyanin equilibria, total phenolics, free and molecular $\mathrm{SO}_{2}$, “Chemical Age." J Sci Food Agric 28:279-287.

Spayd SE, Wample RL, Evans RG, Stevens RG, Seymour BJ and Nagel CW. 1994. Nitrogen fertilization of white Riesling grapes in Washington. Must and wine composition. Am J Enol Vitic 45:34-42.

Striegler RK and Lake CB. 2002. Minimal input production systems affect yield and juice quality of 'Sunbelt' grapes in California's San Joaquin Valley. HortScience 37:867-870.

Treeby MT, Holzapfel BP, Pickering GJ and Friedrich CJ. 2000. Vineyard nitrogen supply and Shiraz grape and wine quality. Acta Hortic 512:77-92.

USS Working Group WRB. 2015. World Reference Base for Soil Resources 2014, update 2015. International soil classification system for naming soils and creating legends for soil maps. World Soil Resources Reports, 106. FAO, Rome.

Wessner LF and Kurtural SK. 2013. Pruning systems and canopy management practice interact on the yield and fruit composition of Shiraz. Am J Enol Vitic 64:134-138.

Yokotsuka K, Nagao A, Nakazawa K and Sato M. 1999. Changes in anthocyanins in berry skins of Merlot and Cabernet Sauvignon grapes grown in two soils modified with limestone or oyster shell versus a native soil over two years. Am J Enol Vitic 50:1-12.

Zhang S, Li Z and Yang X. 2015. Effects of long-term inorganic and organic fertilization on soil micronutrient status. Commun Soil Sci Plan 46:1778-1790

Ziola-Frankowska A and Frankowski M. 2017. Determination of metals and metalloids in wine using inductively coupled plasma optical emission spectrometry and mini-torch. Food Anal Methods 10:180-190. 